\title{
Emergency chest exploration and repair of the right internal jugular vein during Extracorporeal Membrane Oxygenator institution
}

\author{
Imran Hussain ${ }^{1}$, Uthman Aluthman ${ }^{2}$, Jose Fernandez ${ }^{3}$, Luis Zerpa Acosta ${ }^{3}$, and Ali \\ Haneef $^{3}$
}

${ }^{1}$ King Abdulaziz Medical City

${ }^{2}$ King Faisal Specialist Hospital and Research Centre - Jeddah

${ }^{3}$ King Abdulaziz Medical City - Jeddah

September 22, 2020

\begin{abstract}
A 38-year-old female with severe septic shock and multiorgan failure secondary to MDR-ESBL E. coli secondary to septic abortion. She had a miscarriage at 22 weeks of gestation after IVF pregnancy, complicated by cervical tear, developed ARDS, required ventilation, ECMO and CRRT. She had an ECMO cannula induced tear in the right internal jugular vein $1 \mathrm{~cm}$ before joining the subclavian vein to form the innominate vein. She had a cardiac arrest after extracorporeal membrane oxygenation (ECMO) institution, required resuscitation. The iatrogenic Rt Internal jugular vein tear was managed in the cardiac operating room. She was well managed by a multidisciplinary team in the ICU and after a prolonged ICU stay, she was discharged to home.
\end{abstract}

\section{Hosted file}

ECMO Case Report.pdf available at https://authorea.com/users/360905/articles/482447emergency-chest-exploration-and-repair-of-the-right-internal-jugular-vein-duringextracorporeal-membrane-oxygenator-institution 